\title{
COMMENTARX
}

\section{Canadian breast cancer guidelines are as effective as possible under the circumstances}

\section{Eva Grunfeld}

$\infty \quad$ See related article page $77 \mathrm{I}$

$\mathrm{C}$ linical practice guidelines systematically synthesize overwhelming and sometimes conflicting medical research into a cogent statement to guide clinical decisions: However, the million dollar question remains unanswered - are guidelines effective? Systematic reviews, meta-analyses and clinical practice guidelines are all steps on the path to the Holy Grail of consistent, evidence-based decision-making in clinical practice. This, however, does not mean complete uniformity in decision-making, since some variation in care, reflecting local circumstances, clinical judgment and patient particulars, is appropriate. ${ }^{1,2}$ Internationally, there are a number of large organizations focused on guideline development, including the National Institute for Health and Clinical Excellence and the Scottish Intercollegiate Guidelines Network. With respect to cancer guidelines, national, ${ }^{3}$ provincial $^{4}$ and professional ${ }^{5}$ organizations all direct substantial resources toward the development, dissemination and maintenance of guidelines.

Among these guidelines are the Canadian Practice Guidelines for the Care and Treatment of Breast Cancer, ${ }^{3}$ which were supported by Health Canada and written by a Steering Committee through a rigorous process. To date, I6 guidelines have been developed: the first Io were published as a $C M A J$ supplement in $1998,{ }^{3}$ and new guidelines and updates have subsequently been published in $C M A J$ and are available at www.cmaj.ca/cgi/content/full/158/3/DCI. The principal medium for dissemination of the guidelines has been the print and online versions of CMAJ. A companion version for patients is available for each guideline in both English and French on the CMAJ Web site and is distributed through Health Canada, physicians' offices and various other organizations. The Steering Committee is no longer operational owing to the end of funding from Health Canada. Several guideline updates that were on the cusp of completion when funding ended remain unpublished.

In this issue, Steven Latosinsky and colleagues report the + results of a study designed to determine whether the Canadian breast cancer guidelines have been effective in influencing surgical practice. ${ }^{6}$ They examined 4 measures of surgical care in the 3 years before and 5 years after introduction of the guidelines in 1998 (200I for sentinel lymph node biopsy) to determine whether introduction of the guidelines affected either province-wide rates or variation in rates among surgeons in Manitoba. The authors concluded that the rates of the surgical procedures studied were unaffected by introduction of the guidelines. Although there was a reduction in the rate of axillary node dissection in ductal carcinoma in situ after introduction of the guidelines, it was not significant, perhaps because of the small number of cases. The rate of axillary assessment was already appropriately high before guideline introduction; however, the rates of other measures were not high enough (adequacy of axillary node dissection) or were markedly different from rates elsewhere in Canada (breastconserving surgery). ${ }^{7}$

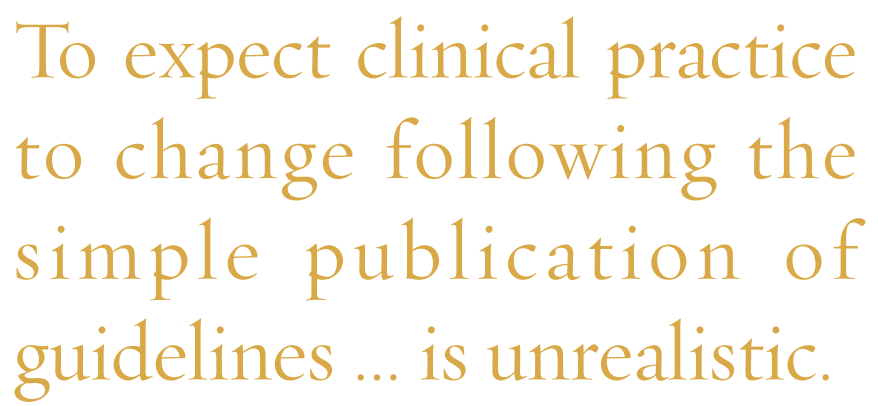

The design of this study is both its strength and its weakness. Its strength is the use of a population-based cancer registry, which is a powerful tool that contains complete staging data for all breast cancer patients in Manitoba dating from 1995. Although all provinces maintain population-based cancer registries, few collect data on cancer stages: this is the strength of the Manitoba registry. The weakness is that the use of a population-based administrative database necessitates an observational design, which makes it impossible to fully understand the extent to which mitigating factors (e.g., patient or institutional factors) affected adherence to the guidelines. The authors conclude that there is clinically important variation in care for the measures studied; however, it is difficult to know the extent to which this can be improved without defining achievable benchmarks for each procedure. ${ }^{8}$ Defining achievable benchmarks would be an important next step in this research.

The findings of the study by Latosinsky and colleagues are consistent with those of other evaluations of surgical care that have found surgical procedure guidelines to be 
less effective than other clinical guidelines. ${ }^{1,9}$ In Canada, guidelines on other aspects of cancer care have been more widely adopted into practice. ${ }^{10-12}$ For some of the surgical procedures studied here, the rates were consistent with good clinical practice even before publication of the guidelines. This reflects the fact that guidelines are a summation of a gradually increasing body of knowledge, much of which had already been adopted in practice. What is disappointing is that both the variations in care and what could be considered less than optimal rates for the other 3 measures persisted despite publication of the guidelines. Does this mean that guidelines are superfluous?

Latosinsky and colleagues rightly conclude that the "no frills" approach to dissemination may have resulted in less than optimal uptake of the guidelines. Disseminating guidelines is very complex ${ }^{2,13}$ and evaluating their uptake even more so. ${ }^{14}$ Just as it is recognized that the dissemination "push" must be multifaceted, so too is the "pull" because clinical decisions are an amalgam of many factors. ${ }^{2,7,13,14}$ To expect clinical practice to change following the simple publication of guidelines, without appreciating the complex factors that may militate against uptake, is unrealistic. Publication of guidelines is one component among many organizational, clinical and professional factors that come into play. ${ }^{1,2,13,14}$ Understanding the complexity of these factors and addressing them in a tailored way, with a special focus on outliers, is the art and the science of knowledge translation. When guidelines are introduced in the context of broader organizational change, they are an effective way to improve care, ${ }^{13,15}$ which shows that guidelines are a means to an end and not an end in themselves.

The National Institute for Health and Clinical Excellence has recognized the need to increase resources for guideline dissemination, given the variable effectiveness of its guidelines. ${ }^{1}$ In light of this, one can conclude that Canada's breast cancer guidelines are as effective as possible, under the circumstances (to paraphrase the famous winning statement from a CBC Radio contest "as Canadian as possible, under the circumstances").
This article has been peer reviewed.

Eva Grunfeld is Director of the Cancer Outcomes Research Program, Cancer Care Nova Scotia, and Professor in the Division of Medical Oncology, Dalhousie University, Halifax, NS.

Competing interests: Eva Grunfeld was a member of the Steering Committee on the Care and Treatment of Breast Cancer (200I-2006). She is the first author of the 2005 update of Guideline 9 ("Follow-up after treatment for breast cancer").

\section{REFERENCES}

I. Sheldon TA, Cullum N, Dawson D, et al. What's the evidence that NICE guidance has been implemented? Results from a national evaluation using time series analysis, audit of patients' notes, and interviews. BMJ 2004;329:999-I004.

2. Cabana MD, Rand CS, Powe NR, et al. Why don't physicians follow clinical practice guidelines? A framework for improvement. JAMA I999;282:1458-65.

3. Steering Committee on Clinical Practice Guidelines for the Care and Treatment of Breast Cancer. Clinical practice guidelines for the care and treatment of breast cancer. $C M A J$ I998; 58 (Suppl 3):I-83

4. Cancer Care Ontario. Program in evidence-based care. Available: www.cancercare.on.ca/index_practiceGuidelines.htm (accessed 2007 Feb 7).

5. American Society of Clinical Oncology. Practice guidelines. Available: www.asco. org/ac/I,I003,_I2-002009,00.asp (accessed 2007 Feb 7).

6. Latosinsky S, Fradette K, Lix L, et al. Canadian breast cancer guidelines: Have they made a difference? CMAJ 2007;I76(6):77I-6.

7. Hébert-Croteau N, Brisson J, Latreille J, et al. Variations in the treatment of earlystage breast cancer in Quebec between 1988 and 1994. CMAJ I999;161:95I-5.

8. Kiefe CI, Weissman NW, Allison JJ, et al. Identifying achievable benchmarks of care: concepts and methodology. Int J Qual Health Care 1998;10:443-7.

9. Rakovitch E, Pignol JP, Chartier C, et al. The management of ductal carcinoma in situ of the breast: a screened population-based analysis. Breast Cancer Res Treat 2007;IOI:335-47.

Io. Ong S, Watters JM, Grunfeld E, et al. Predictors of referral for adjuvant therapy for colorectal cancer. Can J Surg 2005;48:225-9.

II. Chua B, Olivotto IA, Weir L, et al. Increased use of adjuvant regional radiotherapy for node-positive breast cancer in British Columbia. Breast J 2004;10:38-44.

I2. Hébert-Croteau N, Brisson J, Latreille J, et al. Compliance with consensus recommendations for systemic therapy is associated with improved survival of women with node-negative breast cancer. J Clin Oncol 2004;22:3685-93.

I3. Mowatt G, Grimshaw JM, Davis DA, et al. Getting evidence into practice: the work of the Cochrane Effective Practice and Organization of Care Group (EPOC). J Contin Educ Health Prof 2001;21:55-6o.

I4. Grimshaw JM, Shirran L, Thomas R, et al. Changing provider behavior: an overview of systematic reviews of interventions. Med Care 200I;39(Suppl 2):II2-45.

I5. Ray-Coquard I, Philip T, de Laroche G, et al. Persistence of medical change at implementation of clinical guidelines on medical practice: a controlled study in a cancer network. J Clin Oncol 2005;23:44I4-23.

Correspondence to: Dr. Eva Grunfeld, Cancer Care Nova Scotia, $5^{\text {th }}$ floor, Bethune Building, 1278 Tower Rd., Halifax NS $\mathrm{B}_{3} \mathrm{~J}_{3} \mathrm{Z}_{3}$; eva.grunfeld@ccns.nshealth.ca

\section{LEADERSHIP}

$C M A J$ is a founding member of the International Committee of Medical Journal Editors, an organization that is devoted to ensuring the highest integrity in scientific publishing and is a driving force in the mandatory registration of clinical trials. 